\title{
Economics
}

2015; 4(3-1): 1-5

Published online January 23, 2015 (http://www.sciencepublishinggroup.com/j/eco)

doi: $10.11648 /$ j.eco.s.2015040301.11

ISSN: 2376-659X (Print); ISSN: 2376-6603 (Online)

\section{Present and the future of axiomatic theory of boxed pigs}

\author{
Dianyu Jiang \\ Institute of Game Theory with Applications, Huaihai Institute of Technology, No.59 Cangwu Road, Lianyungang, China
}

Email address:

jiangdianyu425@126.com

To cite this article:

Dianyu Jiang. Present and the Future of Axiomatic Theory of Boxed Pigs. Economics. Special Issue: Axiomatic Theory of Boxed Pigs.

Vol. 4, No. 3-1, 2015, pp. 1-5. doi: 10.11648/j.eco.s.2015040301.11

\begin{abstract}
Boxed pigs or rational pigs are well-known stories with many editions of game theory. In order to promote these to a systematic and scientific theory, an axiomatic theory, called L-system of boxed pigs, is established and some special subsystems are deduced from it. In this article, we introduce the background, the main results and the future research plan of axiomatic theory of boxed pigs. This introduction is divided into the following five aspects: appearance of boxed pigs, development and actualities of boxed pigs or rational pigs, boxed pigs in China, L-system of axiomatic theory of boxed pigs, and future research------non L-systems of axiomatic theory of boxed pigs.
\end{abstract}

Keywords: game of boxed pigs, axiomatic theory, L-system, non-L-system

\section{Appearance of Boxed Pigs}

The scholars who study animal psychology and behavior think that the equilibrium situation formed by the game amounts to the animals tending to the results calculated by game theory. However, the facts do not show that the animals know game theory. In fact, the reasons for the animals' behavior lie in genetic and natural selection (e.g., Dawkins, 1976; Smith, 1982; and Dawkins, 1986).

Two psychologists, Baldwin and Meese (1979), did a famous experiment. They put two pigs, a big one and a small one, into a pigsty with a lever at one end and a trough at the other end. When the lever was pressed, a serving of pig feed would appear in the trough. They then observed the behaviors of the pigs. The final result was that the big one pressed the lever and the small one waited by the trough.

Rasmusen (1989) introduced the example in his book on game theory called Boxed Pigs. He refined the model, the data set of which is according to Brockmann (1979), as follows. Two pigs are put in a Skinner box with a special panel at one end and a food dispenser at the other. When a pig presses the panel at a utility cost of 2 units, 10 units of food are dispensed. One pig is "dominant" (let us assume he is bigger), and if he gets to the dispenser first, the other pig will only get his leavings, worth 1 unit. If, instead, the small pig arrives first, he eats 4 units, and even if they arrive at the same time, the small pig gets 3 units. The following game summarizes the payoffs for the strategies "press the panel" and "wait by the dispenser."

$$
\left.\begin{array}{cccc} 
& \multicolumn{2}{c}{\text { Small Pig }} \\
\multicolumn{1}{c}{\text { Press }} & \text { Wait } \\
\text { Big Pig } & \text { Press } & {[(5,1)} & (4,4) \\
& \text { Wait } & {[9,-1)} & (0,0)
\end{array}\right]
$$

We will say that the model is called the Rasmusen Model.

\section{Development and Actualities of Boxed Pigs or Rational Pigs}

John McMillan (1992, pp. 13-15) rewrote Boxed Pigs as Rational Pigs. He rewrote the story into the following form.

Two pigs, one dominant and the other subordinate, are put in a box. There is a lever at one end of the box which, when pressed, dispenses food at the other end. Thus, the pig that presses the lever must run to the other end; by the time it gets there, the other pig has eaten most, but not all, of the food. The dominant pig is able to prevent the subordinate pig from getting any of the food when both are at the trough. Assuming the pigs can reason, which pig will press the lever?

For the sake of definiteness, let us attach some hypothetical numbers to this game. Suppose 6 units of grain are delivered whenever the lever is pushed. If the subordinate pig presses the lever, the dominant pig eats all 6 units, but if the dominant pig pushes the lever, the subordinate pig eats 5 of the 6 units before the dominant pig pushes it away. To fill in all the possibilities, we must make some assumption about what 
happens in the unlikely event that both press the lever simultaneously. Suppose the subordinate pig can run faster, so if both press, it gets 2 units of the food before the dominant pig arrives. Finally, suppose pressing the lever and running to the other end requires some effort, the equivalent of one-half unit of food. Our game, then, is represented by the following matrix (with the first number in each pair being the subordinate pig's amount of food and the second the dominant pig's):

$$
\left.\begin{array}{cccc}
\multicolumn{3}{c}{\text { Dominant Pig }} \\
\text { Subordinate Pig } & \text { Press } & \text { Don't Press } \\
& \text { Don't Press } & {[(1.5,3.5)} & (4,4) \\
(5,0.5) & (0,0)
\end{array}\right]
$$

Susan M. Mudambi (1996) said that "The big pig can run faster and eat faster than the little pig, so the little pig knows it will do better if it gets to the dispenser before the big pig" (p. 701). She said also, applying the pigs to a retail scenario, "The Boxed Pigs game predicts that if the innovation costs are high, the small retailer's best strategy is to monitor innovation investments by the large retailer, modify its own operation accordingly, and receive a small residual benefit" (p. 702). This shows that she realized that the big pig can run faster and eat faster than the little pig and that the two pigs' strategy choices involve costs. However, Mudambi's analysis is qualitative.

Maxwell B. Stinchcombe (2002) wrote in a footnote that he first read about the rational pigs game in John McMillan's book (1992). Perhaps Maxwell thought that McMillan's model had unreasonable places (in fact, McMillan said that "we must make some assumption about what happens in the unlikely event"). For example, McMillan said,

"Suppose the subordinate pig can run faster so, if both press, it gets 2 units of the food before the dominant pig arrives." Thus, Maxwell (2002, pp. 20-21) improved McMillan's model as follows. There are two pigs, one big and one little, and each has two actions. Little pig is player 1, big pig is player 2, and the convention has options with 1's being the rows, 2's the columns, and payoffs $(x, y)$ meaning " $x$ to $1, y$ to 2 ." The story is of two pigs in a long room; a lever at one end, when pushed, gives food at the other end; the big pig can move the little pig out of the way and take all the food if they are both at the food output together; the two pigs are equally fast getting across the room, but when they both rush, some of the food, $e$, is pushed out of the trough and onto the floor where the little pig can eat it, and during the time that it takes the big pig to cross the room, the little pig can eat $\alpha$ of the food. This story is interesting when $b>c-e>0, c>e>0,0<\alpha<1,(1-\alpha) b-c>0$. We think of $b$ as the benefit of eating and $c$ as the cost of pushing the lever and crossing the room.

$$
\begin{array}{cccc}
\multicolumn{4}{c}{\text { Big Pig }} \\
\text { Push } & \text { Wait } \\
\text { Little Pig Push } & \text { Wait } & {\left[\begin{array}{ll}
(-c+e, b-e-c) & (-c, b) \\
(\alpha b,(1-\alpha) b-c) & (0,0)
\end{array}\right]}
\end{array}
$$

In order to facilitate comparing the symbols with those used by the book, we rewrite $b$ as $q$ and take the transposition of the above matrix. Then the payoff matrix becomes

$$
\begin{array}{cccc}
\multicolumn{4}{c}{\text { Little Pig }} \\
\text { Push } & \text { Wait } \\
\text { Big Pig } & \text { Push } & {\left[\begin{array}{cc}
(q-e, e-c) & ((1-\alpha) q-c, \alpha q) \\
(q,-c) & (0,0)
\end{array}\right]}
\end{array}
$$

This model we will call the Maxwell Model.

\section{Boxed Pigs in China}

Rasmusen's model has economics background but is boring in mathematics. Before 1996, every scholar interested in game theory in China was a mathematician. Therefore at that time almost nobody in China knows boxed game. Zhang(1996) introduces Rasmusen's model. However he used the name "Rational pigs" which was given by McMillan. Since the simple story without mathematical formulas can be easily understood by humanists, the story "game of rational pigs" immediately attracted the humanists' attention in China and so the literatures in Chinese to use the story have increase sharply. However the grades of those literatures are low.

\section{L-system of Axiomatic Theory of Boxed Pigs}

In internet, Rasmusen's story is said to be "Game Theory on Rational Pigs". However, in fact, all these models are only "stories", instead of "theories" because they do not have any basic element of logic, such as concept, judgment, reasoning and argument, such as "big pig", "small pig", and the difference degree between the two pigs.

In order to improve the stories into a systemic and scientific theory, we must use axiomatic methods, instead of stories.

\subsection{Main Contents}

\subsubsection{General Situation}

Jiang (2005) ( $L$-system of Boxed Pigs and its Deductive Subsystems, $0 \leq \mathrm{L} \leq 1)$ established L-system of axiomatic theory of boxed pigs and some deductive sub-systems were obtained from it, such as simple K-systems, instant K-systems and timing $\mathrm{K}$-systems, $\mathrm{K}=0,1$. Finally, the method to change a game among many pigs (can be infinitely many) into a game between a big pig and a small pig and applicable degree of the method are given.

\subsubsection{Basis}

a. Theoretical Basis: Situation analysis of double action games with entropy (See Jiang (2008-2011), and Jiang (2012c)).

b. Basis on Previous Work: See Jiang(2012a,b), Jiang(2013), Jiang et al.(2013), Jiang et al.(2014), and Sci.and tech. Institute of China and OR society of China (2013).

c. Research Method and Technical Route: See Application 
Report of the National Natural Science Foundation of China in 2013.

\subsubsection{Basic Concepts}

Instant system: The pedals are pressed once, the food is sprayed in the feeding trough immediately.

Timing system: The numbers of the food obtained by one or two of these pigs pressing the panel are functions of the time that the panel is pressed and similarly for the cost paid by laborer (s).

Simple system: The numbers of the food obtained by the small pig, the big pig and the two pigs are equal and the cost pain by each of the two pigs is equal as well.

Non-simple system: The sequence of numbers of the food obtained by the small pig, the big pig and the two pigs is monotonic non-decreasing and the cost pain by the big pig is not smaller than that done by the small pig.

Peace level $0 \leq \mathrm{L} \leq 1)$ : A parameter to describe the degree of the two pigs' friendship. Special background: $L=0$ : For a non-patented technology development game, the factory to wait imitation runs orders to promote the sale of his future imitations; $\mathrm{L}=1$ : For a non-patented technology development game, the factory to wait imitation will begin imitation after the successful development of another factor.

Applicable degree: Degree that a game amount many pigs (can be infinitely many) can be changed into a game between one big pig and one small pig. It is a non-negative real number. In particular, when it is equal to zero, the change method is not feasible.

\subsubsection{Basic Theory}

a. Big Pig and Small Pig: Precise definitions of a big pig and a small pig and the relation between degree of size difference of the two pigs and the results of the game are given.

b. Inclusion relations of the systems: Simple system $\subset$ Instant system $\subset$ Timing relation $\subset$ L-system.

c. Labor enthusiasm theorem: In certain condition, 1) the small "hitchhiking" if and only if the big pig's labor brings profit and the small pig's that does loss, and 2) when the small pig's labor brings profit, his labor enthusiasm is higher than the big pig's that (The theorem is supported by actual cases).

d. Mechanism adjustment: Adjust some indices to overcome the small pig "hitchhiking".

e. Mechanism control: Set some indicators such that the two pigs' labor enthusiasms to conform intended targets.

f. Situation distribution: Order of probabilities of the two pigs' action profits.

g. Game amount many pigs: Change a game amount many (can be infinitely many) pigs into a game between one big pig and one small pig.

\subsubsection{Game between One Big Pig and One Small Pig}

One big pig and one small pig are put in a special pigsty with one trough under a food dispenser and panels on the two sides of the pigsty. Assume the big pig presses on the panel for $t_{b}$ time units and the small one for $t_{s}$. The dispenser spews food into the trough when the panel is pressed for time $t_{0}$. Either the two pigs press the panel at the same time or one of them presses the panel and the other one waits by the trough. If they press the panel at the same time, either eats immediately once he arrives at the trough. $q_{b}\left(t_{b}\right), q_{t}\left(t_{b}, t_{s}\right)$ and $q_{s}\left(t_{s}\right)$ units of food are spewed into the trough, and the quantity of food eaten by the big pig are $b, t$, and $s$ when the big pig presses the panel alone, the two pigs press it together, and the small pig presses it alone, respectively. The big pig pays cost $c_{b}\left(t_{b}\right)$ if he presses the panel, and the small pig pays cost $c_{s}\left(t_{s}\right)$ if he does.

A system is said to be 0 -peace if it satisfies the 0 -peace assumption: The waiting pig immediately eats the food once he sees it. A system is said to be 1-peace if it satisfies the 1-peace assumption: If one of them presses the panel, the other one waits for the laborer to eat the food together with him.

\subsubsection{Outlooks and Prospects}

Because the topic of this book comes from applications to economic management problems, it will have broad application prospects, mostly likely in the following three areas.

a. Mathematical economics and management science. The phenomenon of the boxed pigs permeates every corner of society, politics, economy, life, and so on. For example, labor enthusiasm theorems are new economic laws. Our principle can be used to control and adjust social members' labor enthusiasm. We anticipate that this book will likely promote research on mathematical economics and management science.

b. Animal behavior and experimental game theory. Animal psychologists may promote Baldwin and Meese's experiment (1979) based on our theory. Before performing the experiment, the animal psychologists should know the following.

(a) Some indicators such as the quantity of food into the trough (or briefly QFT), the distance between the trough and the panel (briefly, DTP) and costs and so on need be pre-set.

(b) The two pigs can eat the food within the trough together, i.e., the big pig cannot bully the small one.

(c) The two pigs' running velocities and eating velocities must be measured before the experiment.

(d) The two pigs can be replaced by other animals such as two dogs, two cats and so on.

Based on many research studies, one can compare the stable situation and theoretical calculation and analyze the reasons for differences, such as intelligence, psychological and genetic factors, and so forth. Therefore, this book puts forward some new research topics to animal psychologists and experiment game theory scholars.

c. Rise of applied research of axiomatic theory of boxed pigs. The traditional model of boxed pigs has been applied in various fields, including economic management. However, because there was no strictly scientific theory of boxed pigs, the quality of the research is low. The lack of theoretical results has hindered the progress of application research. Thus, 
we anticipate that axiomatic theory of boxed pigs will promote the applied study of the boxed pigs and will open up a more profound and scientific research field.

\subsection{Academic Evaluation about Research Signification and Creativity}

As everyone knows, significance and creativity in one's research result in a life of academic achievements. So far, 30 experts have reviewed this study. The research significance and creativity of the study obtained 29 experts' consistent affirmation. However, in all the inspection reports of the National Natural Science Foundation of China in 2013, the fifth reviewer (in fact, it is very clear that he did not read my application report) wrote that "The applicant reviewed the research significance of his own project, and he thinks that his own project has the original innovation thought and exploratory. However this reviewer does not think so." Thus, the reviewers to negate my research significance and creativity are less than $3.3 \%$ of the total number who have examined them. This is no wonder because a new academic thought has to accept a long time contending and needing to overcome all kinds of resistance.

\subsection{The shortage of Research Funding}

In recent years, the shortage of research funding has forced me into trouble. I do not have money to attend academic conferences and to publish papers to exchange the progress of my axiom theory of the boxed pigs. My application to NNSFC in 2012 was refused based on a reviewer's opinion is that "this project does not belong to the international research hot spot." My application to NNSFC in 2013 was refused again based on the fifth reviewer denying my innovativeness and the significance of my research. Even the lower-grade foundation project, the Natural Science Foundation of Jiangsu Province, refused my applications two times in 2008 and 2012 without any appraisal report.

\subsection{International Support}

God never shuts one door but he opens another. Mother's cruel weaning can not kill her life hard baby. The poor baby, axiomatic theory of boxed pigs, in the time of crisis was supported by international academic field and international press field. At present, their support includes the following three aspects:

(1) Columbia International Publishing of the United States published the monograph "L-system of Boxed Pigs and its Deductive Subsystems", Jiang (2015), and provided the founds for the publication of this book.

(2) International Journal of Advanced Computing published freely our team's paper, Jiang et al.(2014).

(3) Another international academic publishing company of the United States, Science Publishing Group, invited me again and again to set freely the special issue "Axiomatic Theory of Boxed Pigs" in the international Journal "Economics" and hire me to be its lead guest editor. See:

http://www.sciencepublishinggroup.com/specialissue/1770
01.

\subsection{Attention and Support of OR field of China}

Axiomatic Theory of Boxed Pigs has obtained attention and support of OR field of China, which is embodied in the following two aspects:

(1) Sci.and Tech. Institute of China and OR Society of China (2013), a programmatic authority literature of OR society of China, introduced the research progress of axiomatic theory of boxed pigs.

(2) A special topic speech with the title "Introduction to Researching Progress of Axiomatic Theory of Boxed Pigs" was invited by OR society of China in 2014 (ORSC2014).

\section{Future Research--------Non L-systems of Axiomatic Theory of Boxed Pigs}

\subsection{Incompleteness of L-System}

(1) Purpose: Try to find simple, instant and timing $\mathrm{K}$-systems, $\mathrm{K}=0,1$, which are not deduced from L-system.

(2) Progress: At present we have found that these non-deductive systems of L-system exist and that there no inclusion relation between the instant system and timing system. However, the simple systems can be deduced from them and L-system $(\mathrm{L}=0,1)$, respectively.

\subsection{Negative L-Systems and Super L-Systems}

In the L-system, $\mathrm{L}$ satisfies the condition $0 \leq \mathrm{L} \leq 1$. Next work is extending $\mathrm{L}$ such that either $\mathrm{L}<0$ or $\mathrm{L}>1$.

\subsubsection{Negative L-Systems $(L<0)$}

It can be used to describe the game that non-laborers can get in advance profit from laborers. For example, when a small developer in a remote area knows that a big one will develop a large project there, such as building big shopping malls, a large square, residential areas, and so on, the small developer will raise his prices, and his commercial housing becomes hot in sales although those large projects may not be built for many years.

\subsubsection{Super L-Systems $(L>1)$}

It can be used in the field of technical innovation. For example, for non-patented technology, if its technology difficulty is very great, then it needs a long time from imitation to sale. For patent technology, after the developer gains his profit and enjoys the patent protection, the imitators can be allowed to freely copy the productions and sell them.

\subsection{L-Negative Systems}

In an L-system, the quantity of food into the trough (or briefly QFT) in a simple instant L-system is always assumed to be positive, i.e., $\mathrm{q}>0$. And the laborer needs to pay positive cost $c>0$, i.e., he can suffer losses. However, there is another case in a social system. When a pig presses the panel, some negative public interest, called also a public nuisance may 
occur, i.e., $\mathrm{q}<0$. And he needs to pay the negative cost, $\mathrm{c}<0$, i.e., he gets a positive benefit.

L-negative system can be found from the games that some players, called black sheeps, harm public interests for their own benefit.

\section{References}

[1] Baldwin B.A.,Meese G.B.(1979), Social behavior in pigs studied by means of operant conditioning. Animal Behavior,27(3), 947-957.

[2] Brockmann H.J., Dawkins R., Grafen A.(1979), Evolutionarily stable nesting strategy in a digger wasp. Journal of Theoretical Biology. 77, 473-496.

[3] Dawkins R. (1976), The Selfish Gene. Oxford: Oxford University Press, 1976.

[4] Dawkins R.(1986), The Bind Watchmaker. Harlow, Longman.

[5] Jiang D.Y.(2008a), Static,completely static, and rational games of complete information and their different Nash equilibria, Int $\mathrm{J}$ of Innovative Computing, Information and Control, 4(3), 651-660.

[6] Jiang D.Y.(2008b), Theory of Games with Entropy and its Applications. Beijing: Science Press, (in Chinese).

[7] Jiang D.Y.(2010a), Analysis of Optimal Situation Distributions in a $2 \times 2$ Bi-matrix Game, International Journal of Innovative Computing, Information and Control, 6(7), 3229-3238.

[8] Jiang D.Y.(2010b), Marginal-able Strong Correlated Equilibria in a 3-Person 0-1 game in form $(\Delta \mathrm{S}(0), \Delta \mathrm{S}(1), \Delta \mathrm{S}(2))$, ICLSIM, 469-473.

[9] Jiang D.Y.(2010c), Situation Analysis of Double Action Games with Entropy. New York: Science Press USA Inc.

[10] Jiang D.Y.(2010d), Situation distribution on a symmetrical 3-person 0-1 game with entropy, BIFE. 233-237.

[11] Jiang D.Y.(2010e), Situation distributions in a special 3-person 0-1 game with entropy, ICIC Exprsss Letters. 4(5),1465-1469

[12] Jiang D.Y.(2011), Situation analysis method of a double action symmetrical 3-person game, Journal of Systems Engineering. 26(5), 608-613. (in Chinese)
[13] Jiang D.Y.(2012a), Most probable situations in strong Rasmusen Axiom system for boxed pigs, Systems Engineering. 30(5), 96-100. (in Chinese)

[14] Jiang D.Y.(2012b), Possibilities of situation of boxed pigs based on peace-strong cost assumption. Journal of Systems Science and Mathematical Sciences. 32 (9), 1145-1154. (in Chinese)

[15] Jiang D.Y.(2012c). Situation Analysis and Trick Theory on Games with Entropy (1st Vol, 2nd Vol.). Beijing: Science Press, 2012 (in Chinese). (in Chinese)

[16] Jiang D.Y.(2013), Axiom system for Resmusen boxed pigs and game of technology innovatios, Journal of systems Engineering. 28(2),180-186. (in Chinese)

[17] Jiang D.Y., Jiang M.Q., Hu L., and Zhu X.Y.(2013), Enthusiasm for labor about axiomatic system on boxed pigs under background of time-consuming technology developments, Operations Reserch and Management Science, 22(5):146-152.

[18] Jiang D.Y., Shao Y.B., Zhu X.Y., Matsuhisa T. (2014). Adjustment of the small pig alone abdicating in a mathematical system of rational pigs. Journal of Advanced Computing.3(2):82-97.

[19] Jiang D.Y.(2015). L-system of Boxed Pigs and its Deductive Sub-systems. Columbia: Columbia International Publishing.

[20] John McMillan.(1992), Games, Strategies, and Manager, Oxford, New York: Oxford Univ. Press.

[21] Maxwell B.Stinchcombe(2002). Notes for a Course in Game Theory (Lecture), Fall Semester.

[22] Maynard Smith J.(1982), Evolution and the Theory of Games. Camb: Camb. Univ. Press, 1982.

[23] Rasmusen E.(1989), Games and Information: An Introduction to Game Theory. New York: Wiley- Blackwell, 1st ed., 1994, 2nd ed., 2001, 3rd ed., 2006, 4th ed.

[24] Sci.and Tech. Institute of China and OR Society of China (2013), Report Advances in Operations Research. Beijing: China Science and Technology Press, pp.149-150. (in Chinese)

[25] Susan McDowell Mudambi (1996), The games retailer play, Journal of Marketing Management, 12: 695-706.

[26] Zhang W.(1996), Theory of Games and Information economics, Shanghai: Shanghai people press, (in Chinese). 